\title{
EFEITOS DA BIOMEMBRANA DE LÁTEX DE SERINGUEIRA NA CICATRIZAÇÃO DE FERIDAS EXPERIMENTAIS EM COELHOS
}

\author{
João Paulo Pereira ROSA ${ }^{1}$
}

\author{
${ }^{1}$ Mestre em Biotecnologia.coord.farmacia@unincor.edu.br
}

Recebido em: 09/05/2016 - Aprovado em: 18/09/2016 - Disponibilizado em: 18/12/2016

\begin{abstract}
RESUMO:
$\mathrm{Na}$ literatura, há relatos de que um novo biomaterial originado de planta, a membrana de látex natural de seringueira (Hevea brasiliensis), teria efeitos de estimulação de angiogênese e melhoria da cicatrização de feridas. Este trabalho estudou os efeitos deste biomaterial sobre a cicatrização de feridas experimentais em orelhas de coelhos albinos, segundo o modelo de Ahn e Mustoe (1990). Foram usados quatro coelhos albinos machos, com idade de 1,5 ano e peso entre 2.560 e 2.720 g. Após anestesia com xilazina intramuscular e tricotomia da face interna das orelhas, foram realizadas, com um punch circular de $5 \mathrm{~mm}$ de diâmetro, quatro feridas em cada orelha, de espessura cutânea total, perfazendo um total de 32 feridas. Em cada orelha, a Ferida 1 foi o controle, recebendo tratamento apenas com solução de cloreto de sódio a $0,9 \%$. A Ferida 2 foi coberta por um segmento circular de látex, extraído de luva cirúrgica esterilizada, tendo o mesmo diâmetro da ferida. A Ferida 3 foi coberta por um segmento circular de biomembrana de látex (Biocure®), também com o mesmo diâmetro. Nas Feridas 2 e 3, o curativo foi fixado com fita microporosa. As Feridas 1 a 3 tiveram seus curativos feitos diariamente por sete dias. A Ferida 4 foi coberta por segmento circular de biomembrana de látex (Biocure ${ }^{\circledR}$ ), fixada com fita microporosa e retirado somente no final dos sete dias. Os animais foram colocados em gaiolas individuais e observados clinicamente, diariamente, durante sete dias, recebendo água potável e ração ad libitum. Ao final dos sete dias, os animais foram sacrificados por anestesia em dose letal. As áreas com os ferimentos foram removidas das orelhas e fixadas em formaldeído a $10 \%$. De cada ferida, confeccionaram-se cortes histológicos corados com hematoxilina-eosina (HE). Fez-se análise histológica, que quantificou a epitelização, a inflamação e a granulação. Os resultados foram tabulados e analisados estatisticamente (análise de variância e teste de Tukey, $\mathrm{p}<0,05$ ). Não foram observadas diferenças significativas entre os grupos. Concluiu-se que, neste trabalho, a biomembrana de látex natural de seringueira não teve efeitos significantes sobre a cicatrização de feridas experimentais em orelhas de coelhos.
\end{abstract}

Palavras-Chave: Biomaterial. Ferimento. Angiogênese.

\section{EFFECTS OF RUBBER LATEX MEMBRANE IN WOUND HEALING IN RABBITS EXPERIMENTAL}

\begin{abstract}
In literature, there are reports that a new plant-originated biomaterial, the membrane from natural latex of Hevea brasiliensis, could have effects of angiogenesis stimulation and improvement of wound healing. This work studied the effects of this biomaterial on the healing of experimental wounds in rabbitt ears, according to the model of Ahn and Mustoe (1990). Four adult, albine male rabbitts were used, all with age of 1,5 year and weighing between 2.560 and $2.720 \mathrm{~g}$. After anaesthesia with intramuscular xylazine and shaving of the internal surface of the ears, a circular $5 \mathrm{~mm}$ punch was used to produce, in each ear, four wounds of whole skin depth, a total of 32 wounds. In each ear, Wound 1 was the control, being treated only with $0.9 \%$ sodium chloride solution. Wound 2 was covered with a circular latex segment, cut from sterile surgical glove, having the same diameter of the wound. Wound 3 was covered with a circular biomembrane (Biocure $\left.{ }^{\circledR}\right)$ segment, having the same diameter of the wound. In Wounds 2 and 3, the dressing was fixated with microporous tape. In Wounds 1 to 3 , the dressings were daily made during seven days. Wound 4 was covered with a circular biomembrane (Biocure ${ }^{\circledR}$ ) segment, fixated with microporous tape and opened only after seven


days. The animals were placed in individual cages and clinically observed, daily, during seven days, receiving tap water and laboratory food ad libitum. After seven days, the animals were killed with letal anaesthesia. The wound areas were removed from the ears and fixated in $10 \%$ formaldehyde. From each wound, histological sections were performed and stained with hematoxylin-eosin (HE). The histological analysis was performed, quantifying epithelialization, inflammation and granulation tissue. The results were tabulated and statistically analysed (analysis of variance and Tukey's test, $\mathrm{p}<0,05)$. No significant differences were observed among the results in all groups. It was concluded that, in this work, the biomembrane of natural Hevea brasiliensis latex had no significant effects on the healing of experimental wounds in rabbitt ears.

Keywords: Biomaterial. Injury. Angiogenesis.

\section{INTRODUÇÃO}

Muitos vegetais têm uma utilização primordial como fonte de matéria prima para a indústria. É o caso da seringueira (Hevea brasiliensis), originária da Amazônia e fornecedora do látex, a partir do qual se fabrica a borracha natural. Em tempos mais recentes, descobriu-se que esta árvore poderia também gerar produtos com aplicações médicas. Seu látex contém substâncias que podem ser usadas na confecção de biomateriais, gerando, por exemplo, próteses para substituir vasos sangüíneos.

Pesquisas desenvolvidas por Joaquim Coutinho Netto e colaboradores, no Laboratório de Neuroquímica do Departamento de Bioquímica da Faculdade de Medicina de Ribeirão Preto, Universidade de São Paulo (USP), relataram propriedades biológicas de um novo biomaterial originado do látex da Hevea brasiliensis, com possíveis aplicações no tratamento de feridas. Foi fabricada uma biomembrana com o látex, sem submetê-la às temperaturas usadas, por exemplo, na elaboração de luvas cirúrgicas. Efeitos angiogenéticos (estimulação do crescimento de vasos sangüíneos) deste biomaterial foram detectados e publicados na literatura. Tais efeitos podem ser benéficos na estimulação da cicatrização de feridas crônicas, em especial aquelas em que há redução de leitos vasculares. Há, entretanto, muitos aspectos ainda a pesquisar e confirmar.

Pensando nisso, o presente trabalho teve o objetivo de estudar os efeitos da biomembrana de látex de seringueira sobre a cicatrização de feridas experimentais, produzidas em orelhas de coelhos albinos, no modelo desenvolvido por Ahn e Mustoe (1990) e adaptado ao nosso meio. Apresentou como hipótese se a utilização da biomembrana de látex de seringueira influencia a cicatrização de feridas em orelhas de coelhos.

\section{REFERENCIAL TEÓRICO}

\subsection{O processo de cicatrização de feridas}

A cicatrização de feridas, que ocorre após lesão de qualquer natureza, consiste em uma complexa cascata de eventos celulares e 
moleculares, que interagem para que ocorra a repavimentação e a reconstituição do tecido (MANDELBAUM et al., 2003). A cicatrização ocorre em várias fases que se superpõem e se relacionam reciprocamente, constituindo um processo harmônico, único e contínuo (HUNT e GOODSON, 1993).Este processo pode ser analisado de forma mais completa, sendo dividido em cinco fases: coagulação, inflamação, proliferação, contração da ferida e remodelação (FAZIO, 2000).

O processo de coagulação tem início imediato, após o surgimento da ferida. Essa fase depende da atividade plaquetária e da cascata de coagulação (TERKELTAUB; GINSBERG, 1998). Ocorre uma complexa liberação de produtos. Substâncias vasoativas, proteínas adesivas, fatores de crescimento e proteases são liberadas e ditam o desencadeamento de outras fases (CLARK, 1985). A formação do coágulo serve não apenas para coaptar as bordas das feridas, mas também para cruzar a fibronectina, oferecendo uma matriz provisória, em que os fibroblastos, células endoteliais e queratinócitos possam ingressar na ferida (CLARK et al., 1982; GRINNEL et al., 1981).

O macrófago é a célula inflamatória mais importante dessa fase. Permanece do terceiro ao décimo dia. Fagocita bactérias, desbrida corpos estranhos e direciona $\mathrm{o}$ desenvolvimento de tecido de granulação.
Alta atividade fagocitária dos macrófagos é observada após o trauma (DIEGELMANN et al., 1981). A identificação e a quantificação de macrófagos foram consideradas relevantes como forma de avaliação na cicatrização, já que essas células são fundamentais, pois regulam o processo de proliferação, modulando estímulos que vão resultar na síntese de colágeno e, conseqüentemente, na maturação e resistência de uma cicatriz (WITTE e BARBUL, 1997).

Os linfócitos aparecem na ferida em aproximadamente uma semana. Seu papel não é bem definido, porém sabe-se que, com suas linfocinas, têm importante influência sobre os macrófagos.

Além das células inflamatórias e dos mediadores químicos, a fase inflamatória conta com o importante papel da fibronectina (CLARK, 1988). Sintetizada por uma variedade de células como fibroblastos, queratinócitos e células endoteliais, esta proteína adere simultaneamente à fibrina, ao colágeno e a outros tipos de células, funcionando assim como uma espécie de cola, para consolidar o coágulo de fibrina, as células e os componentes de matriz. Além de formar essa base para a matriz extracelular, tem propriedades quimiotáticas na fagocitose de corpos estranhos e bactérias (MOSHER; FURCHT, 1981).

Agentes farmacológicos podem interferir na cicatrização. Prandi Filho et al. (1988) estudaram os aspectos morfológicos e 
morfométricos do processo inflamatório provocado por fio de algodão no subcutâneo de ratos tratados com diclofenaco sódico, administrado por via intraperitoneal, em dose única diária de $10 \mathrm{mg} / \mathrm{kg}$ de peso corporal. A administração da droga foi iniciada após o término da operação e mantida até o momento do sacrifício dos animais, que ocorreu no $7 .^{\circ}$ dia de pós-operatório. Observaram atenuação do processo inflamatório em todas as fases estudadas, caracterizado por diminuição da proporção de leucócitos no $2 .^{\circ} \mathrm{dia}$, de fibroblastos no $7 .^{\circ}$ dia e da proporção de fibras colágenas. Fatureto et al (1989), após implantarem fio de categute simples no subcutâneo de ratos que receberam diclofenaco sódico, também utilizando 10 $\mathrm{mg} / \mathrm{kg}$ de peso corporal, observaram redução do processo inflamatório no $3 .^{\circ}$ e $7 .^{\circ}$ dias e fibrose mais intensa no $15 .^{\circ}$ dia nos animais tratados. Tognini et al. (1998) estudaram, em ratos, o efeito do diclofenaco de sódio na cicatrização de segmento músculoaponeurótico da parede abdominal, utilizando análise histopatológica, observação qualitativa do processo cicatricial e análise quantitativa do colágeno. A droga foi utilizada na dose de $3 \mathrm{mg} / \mathrm{kg} / \mathrm{dia}$, por via intramuscular, durante quatro dias consecutivos, em animais submetidos à laparotomia mediana. Concluíram que a cicatriz da parede abdominal apresentou menor quantidade de fibras colágenas no $7^{\circ} \mathrm{e}$ $14^{\circ}$ dia de pós operatório, quando comparada à do animal do grupo controle. Em experimentação posterior, Tognini (1999), utilizando outra classe de anti-inflamatório não-esteróide (meloxicam), na dosagem de $0,5 \mathrm{mg} / \mathrm{kg}$ por dia, por via intramuscular, durante 4 dias consecutivos, também avaliando a cicatriz abdominal de ratos, concluiu que esta droga não exerceu efeitos deletérios na ferida operatória, quando esta foi analisada por métodos biomecânicos e morfológicos.

$\mathrm{Na}$ fase de fibroplasia, notada 48 horas após a lesão, há invasão de fibroblastos, que se multiplicam e passam a secretar as proteínas características do tecido em reparação (BEVILACQUA e MODOLIN, 1995). À exceção dos ferimentos que atingem apenas superficialmente a epiderme, todos os demais são repostos pela formação de tecido conjuntivo fibroso, que é constituído, na sua quase totalidade, por fibras colágenas (AUN, 1995). O colágeno é o responsável pela força e integridade de todos os tecidos, sendo que a força e a integridade do tecido de reparação residem no tipo e na quantidade de fibras colágenas (KLEINMAN, SIMÕES e GOLDENBERG, 1995). Dividida em três subfases, a proliferação é responsável pelo "fechamento" da lesão propriamente dita. A primeira das subfases da proliferação é a reepitelização. Faz-se a migração de queratinócitos não danificados das bordas da ferida e dos anexos epiteliais, quando a ferida é de espessura parcial, e apenas das margens 
nas de espessura total. Fatores de crescimento são os prováveis responsáveis pelos aumentos das mitoses e hiperplasia do epitélio (CHISTOPHER, 1972). O Fator de Crescimento de Fibroblasto Básico (FCF $\beta$ ) aumentou, em um experimento, a resistência da aponeurose suturada no abdome de ratos (MEDEIROS et al., 2003).Sabe-se que o plano de movimento dos queratinócitos migrantes é determinado também pelo conteúdo de água no leito da ferida. Feridas superficiais abertas e ressecadas reepitelizam mais lentamente do que as ocluídas (WINTER, 1962; HINMAN; MAIBACH, 1963). A segunda subfase da proliferação inclui a fibroplasia e formação da matriz, que é extremamente importante na formação do tecido de granulação. Este é uma coleção de elementos celulares, incluindo fibroblastos, células inflamatórias e componentes neovasculares e da matriz, como a fibronectina, as glicosaminoglicanas e o colágeno. A formação do tecido de granulação depende do fibroblasto, célula crítica na formação da matriz. Longe de ser apenas produtor de colágeno, o fibroblasto produz elastina, fibronectina, glicosaminoglicana e proteases, estas responsáveis pelo desbridamento e remodelamento fisiológicos (VAN WINKLE, 1967). A última subfase da proliferação é a angiogênese, ou crescimento de novos vasos sangüíneos, essencial para o suprimento de oxigênio e nutrientes para a cicatrização. O fibroblasto produz a substância fundamental amorfa - mucopolissacarídeos envolvidos com a produção, tamanho e orientação das fibras colágenas, sendo responsável pela síntese propriamente dita do colágeno (JUNQUEIRA e CARNEIRO, 1993)

A fase de contração corresponde ao movimento centrípeto das bordas da ferida, quando esta é de espessura total, isto é, quando há perda de todas as camadas da pele. Uma ferida de espessura total tem contração mesmo quando se fazem enxertos de pele, que podem diminuir em $20 \%$ o tamanho da ferida. Em cicatrizes por segunda intenção, que são aquelas das feridas abertas, não suturadas nem enxertadas, que fecharão das bordas para o centro, a contração pode reduzir $62 \%$ da área de superfície do defeito cutâneo, na dependência da elasticidade da pele do local (LAWRENCE et al., 1986).

A última das fases consiste na remodelação; ocorre no colágeno e na matriz; dura meses e éresponsável pelo aumento da força de tensão e pela diminuição do tamanho da cicatriz e do eritema. Reformulações químicas e reorganização espacial do colágeno, melhoria nos componentes das fibras colágenas, reabsorção de água são eventos que permitem um aumento da resistência da cicatriz e diminuem, pouco a pouco, sua espessura (LAWRENCE et al., 1986). A maturação da cicatriz se associa a intensa remodelação (BIONDO-SIMÕES, 2000). 


\subsection{Modelo de feridas experimentais em} orelha de coelho

Ahn e Mustoe (1990) desenvolveram um modelo de feridas experimentais em orelhas de coelhos albinos. Estes autores utilizaram 34 coelhos albinos, pesando entre 2,7 e 3,2 kg cada; sendo que os animais foram anestesiados com cetamina (60 $\mathrm{mg} / \mathrm{kg})$ e xilazina $(5 \mathrm{mg} / \mathrm{kg})$, por via intramuscular. Os pêlos da face interna das orelhas foram removidos com tesoura e, depois, com um agente depilatório. Em seguida, foram feitos cortes excisionais circunferenciais, usando um punch de $6 \mathrm{~mm}$, produzindo um total de quatro feridas circulares, de $6 \mathrm{~mm}$ cada, em cada orelha, até o nível da cartilagem. Foram estas, então, feridas cutâneas de espessura total. O número de feridas neste modelo é suficiente para que uma sirva de controle e as demais recebam diferentes tratamentos. Ao final da observação, os animais foram sacrificados, as feridas foram excisadas em bloco, incluídas em parafina e analisadas histologicamente, após coloração pela hematoxilina-eosina (HE), para estudo do processo de cicatrização.

\subsection{Biomembrana de látex natural da} seringueira

O látex da seringueira (Hevea brasiliensis) desde há muito tempo é utilizado para fins industriais, dando origem à borracha natural. Uma biomembrana de látex da seringueira, com finalidade terapêutica foi desenvolvida por Coutinho-Netto no Laboratório de Bioquímica da Faculdade de Medicina da Universidade de São Paulo (USP), em Ribeirão Preto. Em 1996, foi reportado o primeiro resultado da sua utilização experimental como substituto do esôfago cervical de cães(MRUÉ, 1996). Usando látex vegetal e $0,1 \%$ de colágeno, criou-se um tubo sintético, que foi implantado em cães. Embora, após cerca de dez dias, o tubo fosse eliminado junto com as fezes dos animais, exames endoscópicos mostraram neoformação tecidual, especialmente de vasos sanguíneos (neo-angiogênese) no local onde a prótese tinha sido implantada. O método de obtenção do biopolímero parece ser fundamental no processo de angiogênese; foram feitos testes usando luvas e preservativos, que têm como matéria-prima o látex, para avaliar seu comportamento no processo de cicatrização. Estes materiais não tiveram ação. A temperatura de obtenção da biomembrana não pode ser alta, como ocorre na fabricação de luvas e preservativos. Temperaturas altas parecem inativar fatores que seriam angiogenéticos. Os testes foram feitos também em modelo experimental com ovos de galinha embrionados, para avaliar a formação dos vasos, e em orelhas de coelhos, para verificar a rapidez com que ocorre o processo de cicatrização (NETTO e MRUÉ, 2003).As possíveis propriedades indutoras de regeneração tecidual da biomembrana de látex 
levaram a sua utilização experimental como substituto parcial do pericárdio de cães(SADER et al., 2000).

Oliveira et al. (2003) usaram a biomembrana, em conjunto com enxertos de fáscia temporal, para a reconstituição de membranas timpânicas com perfurações resultantes de otite média (miringoplastia). Constataram intensa vascularização na área dos enxertos, relatando que tal neoangiogênese não é costumeira nos enxertos simples de fáscia (sem a biomembrana). Oliveira et al. (2005) utilizaram a biomembrana após o tratamento cirúrgico do pterígio. Constataram que, usando-se o biomaterial sobre a área cruenta resultante da operação, ocorreu $27 \%$ de recidiva do pterígio, contra $8 \%$ utilizando-se transplante de conjuntiva. Dada a natureza vascular do pterígio, pode-se supor que a biomembrana tenha de fato estimulado uma taxa de recidiva maior, quando comparada ao transplante conjuntival.

Existem evidências que sugerem a presença de fatores de crescimento no látex, que aumentariam a vascularização local e a reepitelização de feridas, conforme relataram Frade et al., (2001), baseados nos resultados obtidos após tratamento de úlceras cutâneas flebopáticas crônicas no homem. Estes autores relataram que, clinicamente, houve neo-angiogênese, embora a formação de pele sobre o local atingido ainda dependesse do potencial de cicatrização de cada pessoa, o qual pode variar de acordo com a idade ou outros fatores(FRADE et al., 2002).

\subsubsection{Apresentação comercial e recomendações do fabricante}

A biomembrana existe em apresentação comercial, sob o nome de Biocure ${ }^{\circledR}$. O material informativo que vem junto com o produto informa que se trata de material ativo que induz a formação de novos vasos sanguíneos - angiogênese - na superfície sobre a qual é aplicado, recomendando sua utilização em úlceras crônicas diabéticas, vasculares, de pressão (escaras de decúbito), pós-cirúrgicas ou traumáticas. Segundo o fabricante, a biomembrana deve ser aplicada diretamente sobre a superfície da lesão.

A biomembrana vem embalada em envelope de papel de grau cirúrgico, esterilizada por óxido de etileno. Deve ser removida do envelope, cortada com tesoura esterilizada em tamanho adequado para cobrir integralmente a ferida, mas evitando cobrir a pele sadia ao redor da lesão. A ferida deve ser limpa com solução de cloreto de sódio a $0,9 \%$ e a biomembrana já cortada deve ser colocada diretamente sobre a lesão. A seguir, deve ser recoberta com gaze estéril, para melhorar a área de contato com a lesão e absorver a secreção (NETTO; MRUÉ, 2003). Dependendo do local, pode-se fixar o curativo com atadura ou fita adesiva. 
O fabricante recomenda que, em geral, a primeira troca da biomembrana não deva ultrapassar 24 horas após a colocação. A partir daí, as trocas subseqüentes do Biocure ${ }^{\circledR}$ ficariam a critério do profissional responsável pelo caso. Sempre que houver a troca do curativo externo, a biomembrana usada deveria ser substituída por uma nova.

\section{METODOLOGIA}

Foram usados quatro coelhos albinos machos, com a mesma idade (um ano e seis meses) e peso variando entre $2.560 \mathrm{~g}$ e 2.720 g. Foram pesados em balança eletrônica marca Filizola (para carga entre 0,5 kg e 30 $\mathrm{kg}$, com precisão de 20 g.Foram mantidos em gaiolas no Biotério da UNINCOR. O ciclo claro-escuro, a temperatura e a umidade foram os mesmos do ambiente geral, sem regulagem artificial. Os animais receberam ração e água de torneira ad libitum durante todo o experimento. Cada animal foi anestesiado por aplicação intra-muscular, na face posterior da coxa traseira do lado esquerdo, de $7 \mathrm{mg} / \mathrm{kg}$ de peso de cloridrato de xilazina (Calmiun®).Depois de atingido o plano anestésico, foi depilada a superfície interna de ambas as orelhas com lâmina de bisturi. Utilizando-se um punch de 5 mmforam realizadas quatro feridas em cada orelha, num total de 32 feridas. As feridas foram produzidas a partir de $3 \mathrm{~cm}$ abaixo da extremidade superior de cada orelha, evitando-se atingir os vasos sanguíneos, visíveis por transparência. As quatro feridas de cada orelha compuseram um quadrilátero e foram assim numeradas: Ferida 1 - superior esquerda; Ferida 2 - superior direita; Ferida 3 - inferior esquerda; Ferida 4 - inferior direita. Para distinguir lado, as feridas receberam ainda as letras D (orelha direita) ou E (orelha esquerda). Por exemplo: Ferida 1D - ferida superior esquerda da orelha direita.

Em cada orelha, a Ferida 1 foi o controle, recebendo tratamento apenas de solução de cloreto de sódio a 0,9\%, estéril, e permanecendo aberta. A Ferida 2 foi coberta por um segmento circular de látex, extraído de luva cirúrgica esterilizada, tendo o mesmo diâmetro da ferida. A Ferida 3 foi coberta pela biomembrana de látex (Biocure $\AA$ ), com as mesmas dimensões. Nas três primeiras feridas os curativos foram trocados diariamente por sete dias. A Ferida 4 foi coberta pela biomembrana de látex, sem troca diária, sendo retirada somente no final dos sete dias. As Feridas 2, 3 e 4 foram cobertas por fita microporosa, após passar-se tintura de benjoim na pele vizinha. As Figuras 1 e 2 ilustram estes procedimentos. 


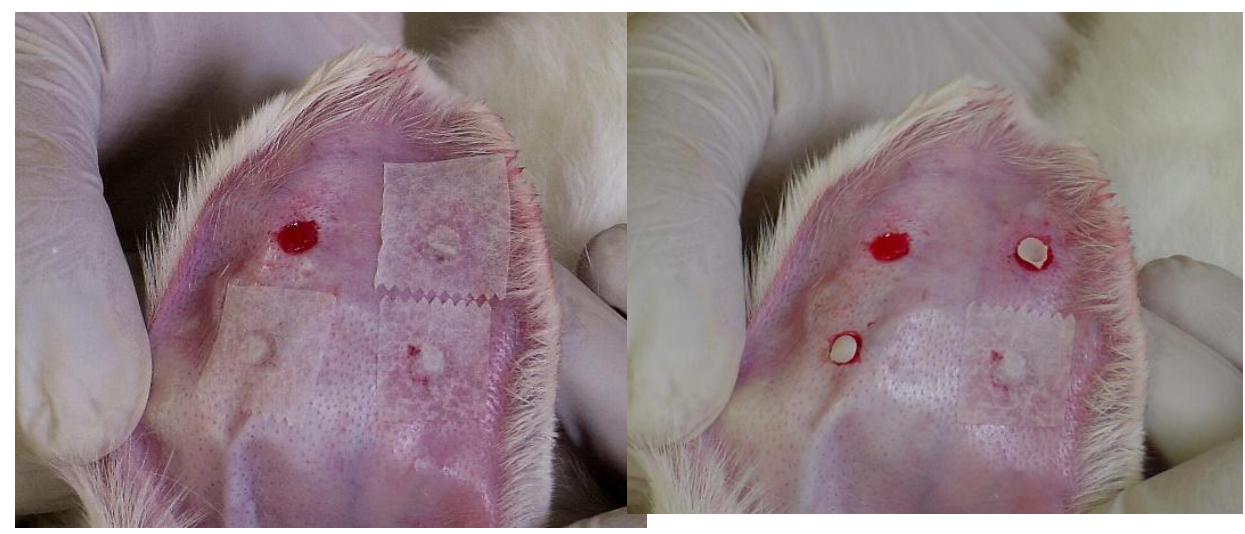

Figuras 1 e 2 - Feridas já tratadas e Feridas 2, 3 e 4 com fixação do látex e biomembrana por fita microporosa.

Os animais foram observados diariamente durante sete dias, recebendo água potável e ração ad libitum. Durante todo o experimento, foi feita observação clínica e fotográfica dos ferimentos. Estes foram mensurados e tiveram observados seus aspectos macroscópicos (FIGURAS 3 a 5).

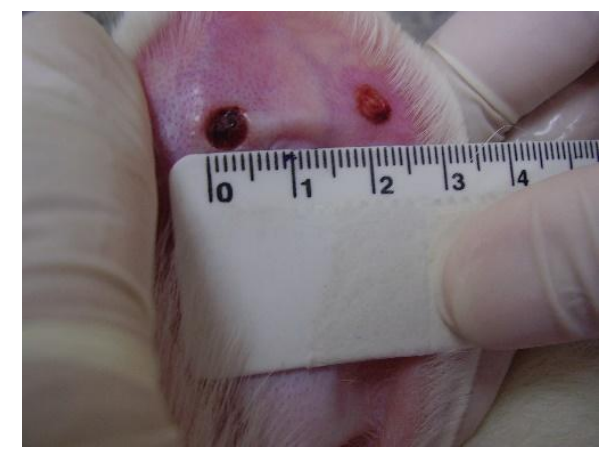

Figura 3 - Observação e medida da Ferida 1 (tratada com solução de cloreto de sódio)

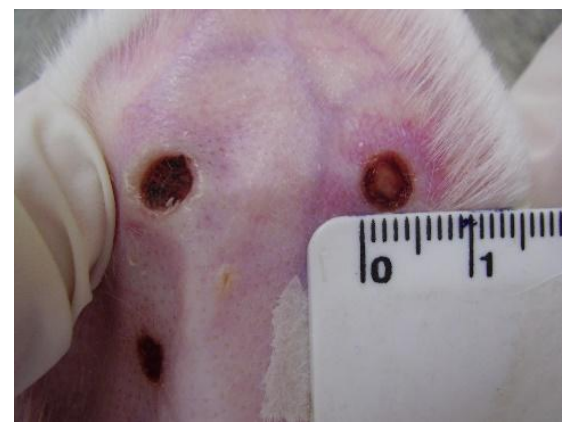

Figura 4 - Observação e medida da Ferida 2 (tratada com látex de luva cirúrgica)

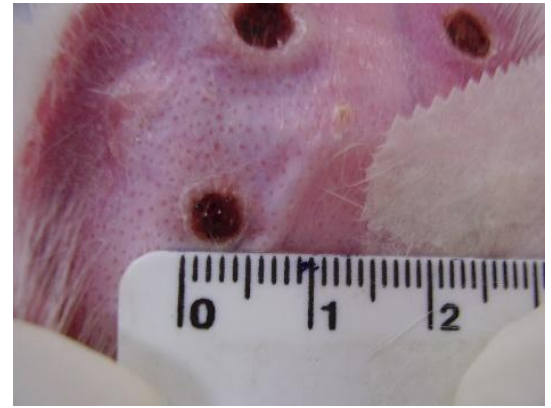

Figura 5- Observação e medida da Ferida 3 (tratada com biomembrana de látextrocada diariamente)

Os animais foram sacrificados por anestesia em dose letal. As áreas com os ferimentos foram removidas das orelhas (FIGURA 6) e fixadas em formaldeído a $10 \%$, sendo posteriormente incluídas em parafina, cortadas e coradas por hematoxilinaeosina (HE).

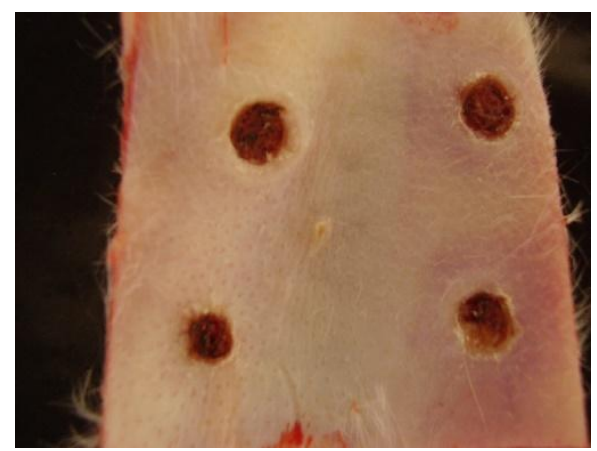

Figura 6 - Segmento da orelha contendo as feridas. 
Fez-se análise histológica da inflamação, epitelização e da granulação das feridas. Estudou-se a presença ou não de reação inflamatória, que foi classificada como aguda, agudo-crônica ou crônica, conforme o tipo de célula inflamatória predominante. A sua intensidade foi classificada em cruzes (+), variando na escala de 1 a 4 cruzes, sendo + ou ++ para intensidade leve/moderada e +++ ou ++++ para intensidade moderada/acentuada; além da presença (+) ou ausência (-) de granulomas de corpo estranho, que eram avaliados em números de granulomas na área cicatricial. A reação inflamatória aguda foi caracterizada pelo predomínio de leucócitos polimorfonucleares e congestão vascular. A reação inflamatória crônica, pela presença de fibroblastos e infiltrado predominante monomorfonuclear (macrófagos, linfócitos e plasmócitos); a reação agudo-crônica, quando havia presença de polimorfonucleares e monomorfonucleares, sem predomínio de nenhuma destas células.A epitelização foi quantificada em: ausente, presente até $1 / 3$ da circunferência da borda da ferida, até $2 / 3$ e completa.A granulação foi quantificada em: estruturas vasculares ausentes, raras, presentes e frequentes.

Para verificar a existência de diferença significativa entre os tratamentos estudados, realizou-se a análise de variância (ANOVA) através do programa SANEST (Sistema de Análise Estatística), com um nível de significância de 5\% de probabilidade. As variáveis qualitativas dos seguintes tratamentos: Tecido de Granulação, Epitelização das bordas da ferida, Inflamação (conforme o tipo de célula predominante) e a Intensidade da Inflamação, foram convertidas para dados quantitativos de acordo com o quadro 1.

Quadro 1 - Variáveis qualitativas transformadas em quantitativas para análise estatística.

Tratamento / Variável Qualitativa/ Variável Quantitativa

\begin{tabular}{|l|l|l|}
\hline Tecido de Granulação & Ausente & 1 \\
& Presente (raros) & 2 \\
& Presente (alguns) & 3 \\
& Presente (freqüentes) & 4 \\
\hline Epitelização das bordas da ferida & Ausente & 1 \\
& Presente até $1 / 3$ & 2 \\
& Presente até 2/3 & 3 \\
& Completa & 4 \\
\hline Inflamação (conforme o tipo de célula predominante) & Ausente & 1 \\
& Aguda & 2 \\
Intensidade da Inflamação & Crônica & 3 \\
& Aguda/Crônica & 4 \\
\hline & Ausente & 1 \\
& Leve & 2 \\
& Moderada & 3 \\
& Acentuada & 4 \\
\hline
\end{tabular}


4 RESULTADOS

Os achados da observação clínica

4.1 Observação Clínica estão sumariados no Quadro 2.

Quadro 2 - Síntese dos achados da observação clínica. Espaços em branco: não houve alterações.

\begin{tabular}{|c|c|c|c|c|c|c|c|c|}
\hline Animal & Ferida & $1 .^{\circ} \mathrm{dia}$ & $2 .^{\circ} \mathrm{dia}$ & 3. $^{0}$ dia & 4. $^{\circ} \mathrm{dia}$ & $5^{0}{ }^{\circ}$ dia & $6^{0} .^{d} \mathrm{dia}$ & $7^{\circ} .^{\circ}$ dia \\
\hline \multirow[t]{8}{*}{1} & 1D & & & & & & & \\
\hline & $2 \mathrm{D}$ & & & & & & & \\
\hline & $3 \mathrm{D}$ & & & & & & & $\begin{array}{l}\text { Pequena } \\
\text { redução }\end{array}$ \\
\hline & 4D & & & & & & & \\
\hline & $1 \mathrm{E}$ & & & & & & $\begin{array}{l}\text { Pequena } \\
\text { crosta }\end{array}$ & \\
\hline & $2 \mathrm{E}$ & & & & & & & \\
\hline & $3 \mathrm{E}$ & & & & & & & \\
\hline & $4 \mathrm{E}$ & & & & & & & $\begin{array}{l}\text { Pequena } \\
\text { redução }\end{array}$ \\
\hline \multirow[t]{8}{*}{2} & 1D & & & & & & & \\
\hline & $2 \mathrm{D}$ & & & & $\begin{array}{l}\text { Pequena } \\
\text { redução }\end{array}$ & & & \\
\hline & $3 \mathrm{D}$ & & & & & & & \\
\hline & 4D & & & & & & & \\
\hline & $1 \mathrm{E}$ & & & & & & & \\
\hline & $2 \mathrm{E}$ & & & & & & & \\
\hline & $3 \mathrm{E}$ & & & & & & & \\
\hline & $4 \mathrm{E}$ & & & & & & & \\
\hline \multirow[t]{8}{*}{3} & 1D & & & & $\begin{array}{l}\text { Pequena } \\
\text { crosta }\end{array}$ & & & \\
\hline & $2 \mathrm{D}$ & & & & & $\begin{array}{l}\text { Pequena } \\
\text { redução }\end{array}$ & & $\begin{array}{l}\text { Pequena } \\
\text { redução }\end{array}$ \\
\hline & $3 \mathrm{D}$ & & & & & & & \\
\hline & $4 \mathrm{D}$ & & & & & & & \\
\hline & $1 \mathrm{E}$ & & & & & & & $\begin{array}{l}\text { Pequena } \\
\text { redução }\end{array}$ \\
\hline & $2 \mathrm{E}$ & & & $\begin{array}{l}\text { Aspecto } \\
\text { esbran- } \\
\text { quiçado }\end{array}$ & & & $\begin{array}{l}\text { Pequena } \\
\text { redução }\end{array}$ & \\
\hline & $3 \mathrm{E}$ & & & & & & & $\begin{array}{l}\text { Pequena } \\
\text { redução }\end{array}$ \\
\hline & $4 \mathrm{E}$ & & & & & & & $\begin{array}{l}\text { Pequena } \\
\text { redução }\end{array}$ \\
\hline \multirow[t]{8}{*}{4} & 1D & & & & & & & \\
\hline & $2 \mathrm{D}$ & & & & & & & \\
\hline & $3 \mathrm{D}$ & & & $\begin{array}{l}\text { Pontos } \\
\text { brancos }\end{array}$ & Idem & Idem & Idem & \\
\hline & 4D & & & & & & & \\
\hline & $1 \mathrm{E}$ & & & & & & & \\
\hline & $2 \mathrm{E}$ & & & & & & & \\
\hline & $3 \mathrm{E}$ & & & & & $\begin{array}{l}\text { Pontos } \\
\text { brancos }\end{array}$ & & \\
\hline & $4 \mathrm{E}$ & & & & & & & \\
\hline
\end{tabular}




\subsection{Exame histopatológico}

\begin{tabular}{|c|}
\hline \\
\hline \\
\hline $\begin{array}{l}\text {-Tecido de Granulação: Em todas as lesões observou-se tecido de granulação, ou seja, } \\
\text { proliferação vascular e fibroblástica, porém houve maior formação do mesmo na Ferida } 4 \\
\text { (biomembrana sem troca), em relação à Ferida } 1 \text { (controle), que apresentava apenas formação de } \\
\text { raras estruturas vasculares. Quanto às Feridas } 2 \text { (luva) e } 3 \text { (biomembrana com troca diária), } \\
\text { observou-se formação de algumas estruturas vasculares. }\end{array}$ \\
\hline $\begin{array}{l}\text {-Epitelização das bordas: Observou-se a reepitelização completa das bordas nas Feridas } 1,2 \text { e } 3 \text {; } \\
\text { porém, na Ferida } 4 \text { (biomembrana sem troca), a reepitelização apresentou-se em menos de } 1 / 3 \text { da } \\
\text { borda da lesão. }\end{array}$ \\
\hline $\begin{array}{l}\text {-Inflamação: Todas as lesões apresentaram processo inflamatório crônico, inclusive o grupo } \\
\text { controle (Ferida 1), porém a Ferida } 4 \text { mostrava-se com área de agudização central. }\end{array}$ \\
\hline $\begin{array}{l}\text {-Intensidade da inflamação: A Ferida } 1 \text { (controle) e a lesão tratada com segmento de luva (Ferida } \\
\text { 2) apresentaram moderado infiltrado linfo-monocitário, enquanto nas Feridas } 3 \text { e } 4 \text { houve } \\
\text { inflamação de intensidade moderada a acentuada. }\end{array}$ \\
\hline \\
\hline $\begin{array}{l}\text {-Tecido de Granulação: Em todas as leões observou-se tecido de granulação, porém com maior } \\
\text { proliferação vascular e fibroblástica nas Feridas de números } 2 \text { e } 3 \text {, em relação ao grupo controle } \\
\text { (Ferida 1), onde havia esparsas estruturas vasculares. Quanto à Ferida 4, observou-se moderada } \\
\text { formação de tecido de granulação. }\end{array}$ \\
\hline $\begin{array}{l}\text {-Epitelização das bordas: Observou-se a reepitelização completa das bordas nas Feridas } 1,2 \text { e } 4 \text {, } \\
\text { porém, na Ferida } 3 \text { (biomembrana com troca diária) a reepitelização apresentou-se em menos de } \\
2 / 3 \text { da borda. }\end{array}$ \\
\hline $\begin{array}{l}\text {-Inflamação: Todas as lesões apresentaram processo inflamatório crônico, inclusive o grupo } \\
\text { controle (Ferida 1), porém a Ferida } 2 \text { mostrava-se com área de agudização central. }\end{array}$ \\
\hline $\begin{array}{l}\text {-Intensidade da inflamação: Observou-se moderado infiltrado linfo-monocitário nas Feridas } 3 \text { e } 4 \\
\text { sendo acentuado na Ferida 2, quando comparadas com o grupo controle (Ferida 1), que mostrol }\end{array}$ \\
\hline
\end{tabular}

\section{Animal número 2}




\begin{tabular}{|c|}
\hline$d a:$ \\
\hline $\begin{array}{l}\text { - Tecido de Granulação: Em todas as lesões observou-se tecido de granulação, com maior } \\
\text { formação do mesmo nas Feridas } 3 \text { e } 4 \text {, quando comparadas com as Feridas } 1 \text { e } 2 \text {, que } \\
\text { apresentaram moderada proliferação vascular e fibroblástica }\end{array}$ \\
\hline $\begin{array}{l}\text { - Epitelização das bordas: Observou-se a reepitelização completa das bordas das lesões apenas no } \\
\text { grupo controle (Ferida } 1 \text { ). Nas Feridas } 2,3 \text { e } 4 \text { houve reepitelização incompleta das bordas na } \\
\text { seguinte proporção: até } 2 / 3 \text {, até } 1 / 3 \text { e até } 1 / 3 \text {, respectivamente. }\end{array}$ \\
\hline $\begin{array}{l}\text { - Inflamação: Todas as lesões apresentaram processo inflamatório crônico, inclusive o grupo } \\
\text { controle (Ferida 1), porém as Feridas } 2,3 \text { e } 4 \text { mostravam-se com área de agudização central. }\end{array}$ \\
\hline $\begin{array}{l}\text { - Intensidade da inflamação: No grupo controle (Ferida 1) observou-se moderado infiltrado linfo- } \\
\text { monocitário. Enquanto a Ferida } 2 \text { mostrou moderada intensidade inflamatória, nas Feridas } 3 \text { e } 4 \\
\text { observou-se acentuado processo inflamatório. }\end{array}$ \\
\hline Orelha direita: \\
\hline $\begin{array}{l}\text { - Tecido de Granulação: Em todas as lesões observou-se tecido de granulação, porém com maior } \\
\text { formação do mesmo nas Feridas } 1 \text { e } 2 \text {. Nas Feridas } 3 \text { e } 4 \text { observou-se moderada formação de } \\
\text { tecido de granulação. Observou-se moderado infiltrado linfo-monocitário nas Feridas } 3 \text { e } 4 \text {, sendo } \\
\text { acentuado na Ferida 2, quando comparadas com o grupo controle (Ferida 1), que mostrou apenas } \\
\text { discreta intensidade inflamatória. }\end{array}$ \\
\hline $\begin{array}{l}\text { - Epitelização das bordas: Não se observou a reepitelização completa das bordas em todas as } \\
\text { lesões; na Ferida } 4 \text { notou-se ausência completa da formação da mesma. Nas demais Feridas (1, } 2 \\
\text { e 3) houve reepitelização incompleta em menos de } 1 / 3 \text { das suas bordas. }\end{array}$ \\
\hline $\begin{array}{l}\text { - Inflamação: Todas as lesões apresentaram processo inflamatório crônico com agudização } \\
\text { central. }\end{array}$ \\
\hline $\begin{array}{l}\text { - Intensidade da inflamação: Nas Feridas 1, } 3 \text { e } 4 \text { observou-se intensa atividade inflamatória, } \\
\text { sendo que na Ferida } 2 \text { houve moderado infiltrado linfo-monocitário. }\end{array}$ \\
\hline
\end{tabular}

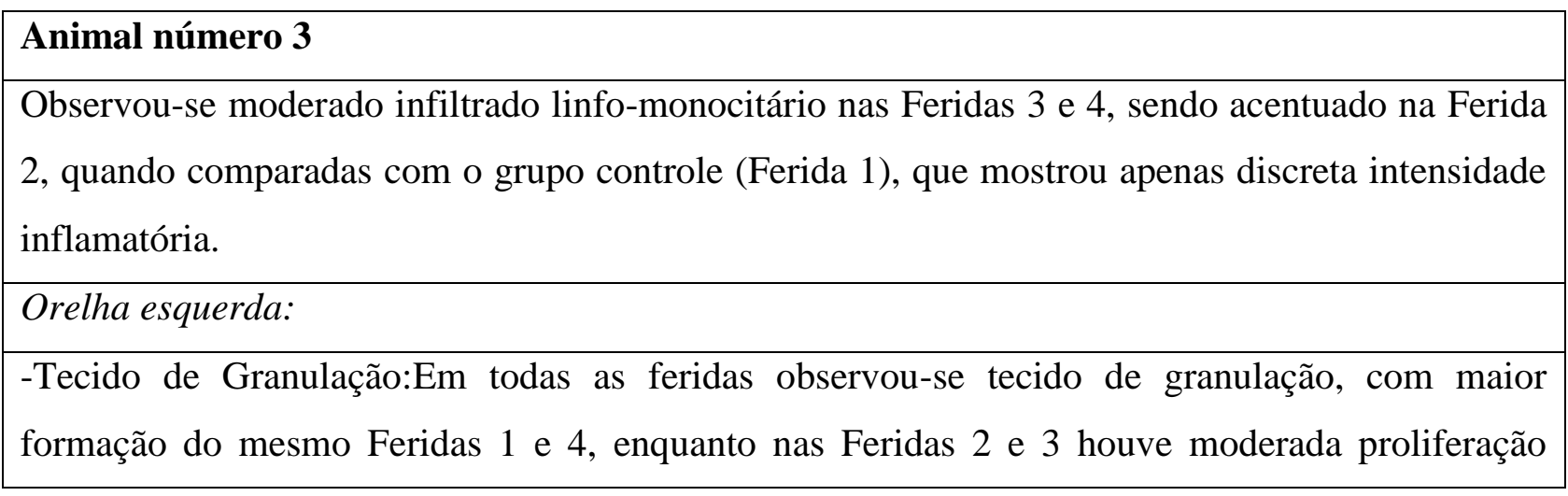


vascular e fibroblástica.

- Epitelização das bordas:Não houve a reepitelização completa das bordas das lesões.Nas Feridas 1,2 e 4 houve reepitelização incompleta das bordas em até 1/3 e, na Ferida 3, a reepitelização ocorreu em até $2 / 3$.

- Inflamação:Todas as lesões apresentaram processo inflamatório crônico com área de agudização central.

- Intensidade da inflamação:No grupo controle (Ferida 1) observou-se freqüente infiltrado linfomonocitário. Já as Feridas 2, 3 e 4 mostraram moderada intensidade inflamatória.

Orelha direita:

-Tecido de Granulação:Em todas as lesões observou-se tecido de granulação, com maior formação do mesmo naquela de número 4.Nas Feridas 1 e 3 houve moderada proliferação vascular e fibroblástica, enquanto na Ferida 2 as estruturas vasculares apresentaram-se de maneira escassa.

-Epitelização das bordas:Observou-se a reepitelização completa das bordas nas Feridas 1 e $2 . \mathrm{Na}$ Ferida 3 houve reepitelização incompleta até 2/3 das bordas, enquanto, na Ferida 4, a mesma ocorreu em até $1 / 3$.

- Inflamação:Todas as lesões apresentaram processo inflamatório crônico, porém as Feridas 3 e 4 mostraram área de agudização central.

- Intensidade da inflamação:Nas Feridas 1, 3 e 4 observou-se moderado infiltrado linfomonocitário, enquanto a Ferida 2 mostrou leve intensidade inflamatória.

\begin{tabular}{|l|}
\hline Animal número 4 \\
\hline Orelha esquerda: \\
\hline - Tecido de Granulação:Em todas as lesões observou-se tecido de granulação, com maior \\
formação de moderada proliferação vascular e fibroblástica \\
\hline - Epitelização das bordas:Observou-se a reepitelização completa das bordas apenas nas Feridas 2 \\
e 3. No grupo controle (Ferida 1) a reepitelização ocorreu em até $2 / 3$ das bordas. Na Ferida 4 \\
houve reepitelização incompleta até $2 / 3$. \\
\hline -Inflamação:Todas as lesões apresentaram processo inflamatório crônico, porém as Feridas 1 e 4 \\
mostraram área de agudização central. \\
\hline - Intensidade da inflamação: Nas Feridas 1,2 e 4 observou-se moderado infiltrado linfo- \\
monocitário, enquanto a Ferida 3 mostrou leve intensidade inflamatória. \\
\hline Orelha direita:
\end{tabular}


-Tecido de Granulação: Em todas as lesões observou-se tecido de granulação, com maior formação do mesmo nas Feridas 2 e 3, quando comparadas com aquelas de números 1 e 4, nas quais houve moderada proliferação vascular e fibroblástica

- Epitelização das bordas:Observou-se a reepitelização completa das bordas das Feridas 1, 3 e 4.Na Ferida 2, houve reepitelização incompleta das bordas na proporção de até 1/3.

- Inflamação:Todas as lesões apresentaram processo inflamatório crônico, porém a Ferida 2 mostrou-se com área de agudização central.

- Intensidade da inflamação:Nas Feridas 2 e 3 observou-se moderado infiltrado linfo-monocitário, enquanto naquelas de números 1 e 4 houve leve intensidade inflamatória.

\subsection{Análise estatística}

Não foram encontradas diferenças significativas entre os grupos, quando comparados entre si, para nenhum dos parâmetros analisados, como se pode ler nos dados a seguir apresentados.

\subsubsection{Avaliação da epitelização da bordas das feridas}

QUADRO DA ANALISE DE VARIANCIA

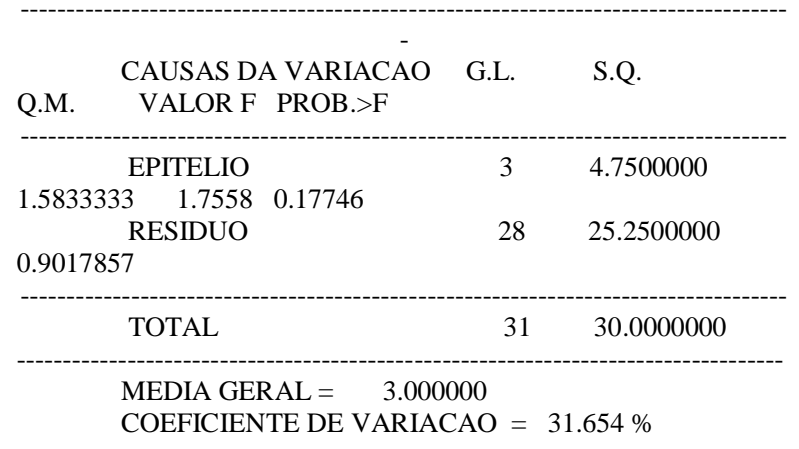

\subsubsection{Avaliação da intensidade da inflamação}

QUADRO DA ANALISE DE VARIANCIA

\begin{tabular}{|c|c|c|c|}
\hline Q.M. & $\begin{array}{l}\text { CAUSAS DA VARIACAO } \\
\text { VALOR F PROB.>F }\end{array}$ & G.L. & S.Q. \\
\hline & INT INF & 3 & 1.8437500 \\
\hline
\end{tabular}

\begin{tabular}{|c|c|c|}
\hline 0.6294643 & 28 & 17.6250000 \\
\hline TOTAL & 31 & 19.4687500 \\
\hline
\end{tabular}

MEDIA GERAL $=2.781250$

COEFICIENTE DE VARIACAO $=28.526 \%$

\subsubsection{Avaliação do tipo de inflamação}

QUADRO DA ANALISE DE VARIANCIA

\begin{tabular}{|c|c|c|c|}
\hline Q.M. & $\begin{array}{l}\text { CAUSAS DA VARIACAO } \\
\text { VALOR F PROB.>F }\end{array}$ & G.L. & S.Q. \\
\hline \multicolumn{2}{|r|}{ INFLAMA } & 3 & 0.6250000 \\
\hline \multirow{2}{*}{\multicolumn{2}{|c|}{$\begin{array}{l}0.2083333 \quad 0.8046 \quad 0.50445 \\
\text { RESIDUO } \\
0.2589286\end{array}$}} & 28 & 7.2500000 \\
\hline & & & \\
\hline \multicolumn{2}{|r|}{ TOTAL } & 31 & 7.8750000 \\
\hline
\end{tabular}

\subsubsection{Avaliação do tecido de granulação}

QUADRO DA ANALISE DE VARIANCIA

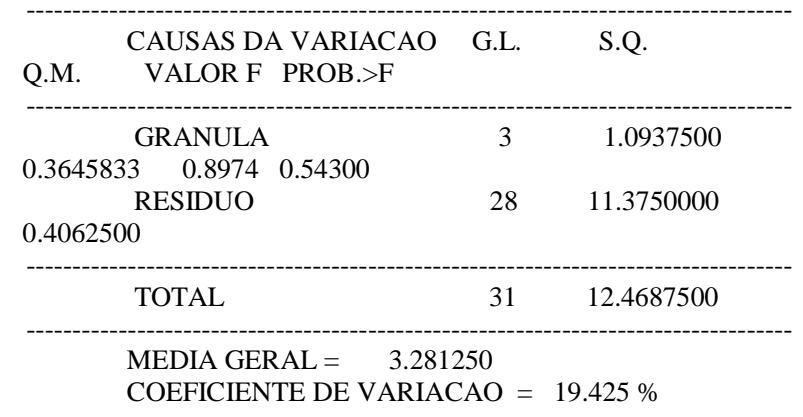




\section{DISCUSSÃO}

A cicatrização é um processo sobre o qual uma longa série de produtos e procedimentos tem sido aplicada, no afã de tentar acelerá-la, especialmente em feridas crônicas. Os leigos utilizam grande número de plantas e produtos delas derivados, por tradição, modismo ou conhecimento popular. Até o presente momento, não se conhecem fitoterápicos de eficácia realmente decisiva na melhora da cicatrização.

Alguns produtos sintéticos da pesquisa científica avançada, como fatores de crescimento, sob o nome químico de becaplermina (PERRY et al., 2002), com ações comprovadas, existem no mercado, mas seu preço é ainda extremamente elevado, inviabilizando sua utilização disseminada, especialmente em países pobres. Processos mecânicos, como a utilização de vácuo sobre ferimentos crônicos, podem, em circunstâncias selecionadas, acelerar a formação de tecido de granulação, parte importante da cicatrização (BRAAKENBURG et.al, 2006), mas também são ainda caros e de uso limitado. Úlceras crônicas podem ser uma grande fonte de gastos; nos Estados Unidos, estima-se que o dispêndio anual somente com aquelas localizadas nos membros inferiores atinja um bilhão de dólares (KHAN e DAVIES, 2006).

Por tais razões, é de grande derivados da flora brasileira, que possam influir significativamente sobre o processo cicatricial. Seu uso reduziria o tempo de cura de feridas cuja evolução pode ser extremamente longa e dispendiosa (THOMAS, 2006), levando a substancial economia de custos e melhoria de qualidade de vida.

Diversos trabalhos científicos, oriundos do grupo de Coutinho Netto, na USP de Ribeirão Preto, relataram que a biomembrana derivada do látex da seringueira teve efeitos favoráveis sobre a cicatrização em diversas circunstâncias experimentais e clínicas, atuando especialmente como indutora da angiogênese (FRADE et al., 2001, 2002 e 2006; MRUÉ, 1996; NETTO e MRUÉ, 2003; OLIVEIRA et al., 2003; SADER et al., 2000). Em feridas crônicas, como as úlceras de perna, um dos principais problemas que retardam a cicatrização é a falta de um leito vascular adequado para possibilitar a epitelização, com cicatrização por segunda intenção, ou a colocação de enxertos de pele parcial ou total (MEYER, 1994). Substâncias que induzam a angiogênese (como a becaplermina, citada acima), são portanto altamente desejáveis. Em trabalhos de Coutinho Netto, foi aventada a hipótese de que o látex da seringueira poderia conter substâncias cuja estrutura química e efeitos farmacológicos se assemelham àqueles de fatores de crescimento.

conveniência pesquisar fitoterápicos, 
O modelo de estudo de cicatrização de feridas em orelhas de coelhos, primeiro publicado por Ahn e Mustoe (1990), oferece diversas vantagens em relação, por exemplo, a modelos que utilizam a pele do dorso de ratos ou camundongos: coelhos são animais dóceis e de fácil manuseio; o animal não tem acesso à face interna de suas orelhas; sendo grandes estas áreas, possibilitam a realização de pelo menos quatro feridas em cada orelha, isto é, no mínimo oito feridas por animal, o que reduz o número de cobaias necessárias, melhora os controles e acelera os experimentos; não há fechamento significativo por contração pura e simples, como ocorre com os ratos e camundongos, pois a pele da orelha do coelho não tem a grande elasticidade e frouxidão daquela do dorso dos outros dois animais mencionados; a padronização dos testes é facilitada e também sua reprodução por outros pesquisadores interessados. Isso levou à adoção do modelo de Ahn e Mustoe (1990) neste trabalho, pela primeira vez na UNINCOR.

Os resultados obtidos nesta pesquisa não mostraram, entretanto, quaisquer diferenças clínicas (de observação macroscópica) ou histológicas estatisticamente significativas dentre os grupos de feridas. Nem mesmo alguma tendência de diferença foi identificada. Tais achados contrastam com aqueles publicados pelo grupo da USP/Ribeirão Preto. Dado que o número de animais e de feridas, no trabalho atual, foi suficiente para fornecer densidade estatística, não é provável que os resultados possam ser contestados com base em insuficiência numérica. Tampouco os estudos histopatológicos, que não diferiram dos métodos clássicos normalmente empregados quando se estuda morfologicamente a cicatrização, apontaram para qualquer diferença ou tendência entre os grupos estudados. Em outras palavras, tanto o uso de solução de cloreto de sódio a 0,9\%, mantendo-se aberta a ferida, quanto sua oclusão por látex de luvas (em cuja manufatura as temperaturas são altas) ou pela biomembrana (seja esta com troca diária ou nenhuma troca por sete dias), levaram ao aparecimento de alguma vantagem de um método sobre o outro.

A continuação de estudos com a biomembrana do látex da seringueira é desejável. Entretanto, seria mais adequado que, antes, substâncias ativas fossem isoladas e, com estas, produtos fossem manufaturados e usados nos experimentos. Desta forma, a alegada presença de substâncias com efeitos semelhantes àqueles de fatores de crescimento poderia ser testada.

Pesquisas não confirmatórias têm tanta validade científica quanto aquelas que confirmam ou descobrem ações de substâncias ou produtos. Nisto se insere o presentetrabalho. Este contribuiu, ademais, para a implantação, na UNINCOR, de um modelo de feridas experimentais que se 
mostrou prático, padronizado e reprodutível nas condições locais, e que poderá servir à continuação de linhas de pesquisa que abordem o uso de fitoterápicos diversos na cicatrização.

\section{CONCLUSÃO}

Os efeitos da biomembrana de látex natural industrializado sobre a cicatrização de feridas experimentais em orelhas de coelhos, se comparados com aqueles de dois outros métodos de tratamento, não foram significativamente diferentes neste trabalho.

\section{REFERÊNCIAS}

AHN S.T.; MUSTOE, T.A. Effects of ischemia on ulcer wound healing: a new model in the rabbit ear. Annals of Plastic Surgery, v.24, p.17-23, jan.1990.

AUN, F. - Problemas clínicos em pacientes cirúrgicos. In AUN, F. \& BEVILACQUA, R.G. - Manual de Cirurgia. 1 ed. São Paulo: E.P.U., 1995. p.147-51.

BEVILACQUA, R.G. \& MODOLIN, M.L.A. - Cicatrização. In AUN, F. \& BEVILACQUA, R.G. - Manual de Cirurgia . 1 ed. São Paulo: E.P.U., 1995. p.01-19.

BIONDO-SIMÕES, M.L.P. et al. O hormônio de crescimento e a concentração de colágeno na cicatriz de feridas cutâneas de ratos. Acta Cirúrgica Brasileira, v.15 (supl.3), p.78-82, 2000.

BRAAKENBURG, A., OBDEIJN, M.C., FEITZ, R., VAN ROOIJ, I.A., VAN GRIETHUYSEN, A.J., KLINKENBIJL, J.H. The clinical efficacy and cost effectiveness of the vacuum-assisted closure technique in the management of acute and chronic wounds: a randomized controlled trial.

Plastic and Reconstructive Surgery, v.118, n.2, p.398-400, ago.2006.

CHRISTOPHER, E. Kinetic aspects of epidermal healing. In: MAIBACH, H.; ROVEE, D. eds. Epidermal wound healing. St Louis: Mosby, 1972.

CLARK, R.A. Cutaneous tissue repair. Basic biologic considerations. Journal of the American Academy of Dermatology, v.13, n.5, p.701-725, nov.1985.

CLARK, R.A. et al. Fibronectin and fibrin provide a provisional matrix for epidermal cell migration during wound reepithelization. Journal of Investigative Dermatology, v.79, n.5, p.264269, nov.1982.

CLARK, R.A. Potential roles of fibronectin in cutaneous wound repair. Archives of Dermatology, v.124, n. 2, p.201-206, fev.1988.

DIEGELMANN, R.F; COHEN, I.K.; KAPLAN, A.M. The role of macrophages in wound repair: a review. Plastic and Reconstructive Surgery, v.68, n. 1, p.107113, jul.1981.

FATURETO, M.C., SIMÕES, M.J., TEIXEIRA, V.P.A. et al. Aspectos morfológicos e morfométricos do processo inflamatório provocados por fio de categute simples no subcutâneo de ratos tratados com diclofenaco sódico. Acta Cirúrgica

Brasileira, v.4, n.1, p.5-9, jan.1989.

FAZIO, M.J.; ZITELLI, J.A.; GOSLEN, J.B. Cicatrização de feridas. In: COLEMAN III W.P. et al. Cirurgia Cosmética - Princípios e

Técnicas. 2 ed. Rio de Janeiro: Revinter, 2.000, p.23-28.

FRADE M.A.C. et al. Avaliação clínica do tratamento de úlceras de perna com a BML. In: CONGRESSO BRASILEIRO DE DERMATOLOGIA, 56. Anais..., Goiânia: 
Sociedade Brasileira de Dermatologia, 2001.p. 132.

FRADE, M.A.C. et al. Induction of leg wound healing by natural latex biomembrane (NLB). Annales de Dermatologie et Vénéréalogie, v.129 (suppl.1), p.S823-S842, 2002.

FRADE, M.A.C. et al. A natural biomembrane as a new proposal for the treatment of pressure ulcers. Medicina Cutanea Ibero Latino Americana, v.34, n.3, p.137-142, 2006.

GRINNELL, F.; BILLINGHAM, R.E.;

BURGESS, L. Distribution of fibronectin during wound healing in vivo.Journal of Investigative Dermatology, v.76, n. 3, p.181-189, mar.1981.

HINMAN, C.D.; MAIBACH, H. Effect of air exposure and occlusion on experimental human skin wounds. Nature, v.200, p.377-379, 1963.

HUNT, T.K. \& GOODSON, W.H. Cicatrização das feridas. In WAY, L. W. Cirurgia Diagnóstico e Tratamento. 9 ed. Rio de Janeiro, Guanabara Koogan, 1993. p.67-75.

JUNQUEIRA, L.C.; CARNEIRO, J. Tecidos conjuntivos. In JUNQUEIRA, L.C.; CARNEIRO, J. Histologia Básica. 7 ed. Rio de Janeiro. Guanabara Koogan. 1993. p 6587.

KHAN, M.N., DAVIES, C.G. Advances in the management of leg ulcers - the potential role of growth factors. International Wound Journal, v.3, n.2, p.113-120, jun.2006.

KLEIMAN, I.; SIMÕES, M.J.; GOLDENBERG, S. - Aspectos atuais do processo de reparação tecidual. Acta Cirúrgica Brasileira., v.10, p.2-8, 1995.

LAWRENCE, C.M.; COMAISH, J.S.; DAHL, M.G. Excision of skin tumours without wound closure. British Journal of Dermatology, v.115, n.5, p.563-571, nov.1986.
MANDELBAUM, S.H. et al. Cicatrization: current concepts and auxiliary resources - Part II. Anais Brasileiros de Dermatologia, v.78, n.5, p. 525-542, 2003.

MEDEIROS, A.C. et al. Ação do fator de crescimento de fibroblasto básico na cicatrização da aponeurose abdominal de ratos. Acta

Cirúrgica Brasileira, v.18 (supl.1), p.5-9, 2003.

MEYER, T.N. Lesões superficiais (feridas). In: SILVA, A.L. Cirurgia de Urgência. 2 ed. Rio de Janeiro: MEDSI, 1994, cap. 25, p. 350-355.

MOSHER, D.F.; FURCHT, L.T. Fibronectin: review of its structure and possible functions.

Journal of Investigative Dermatology, v.77, n.2, p.175-180, ago.1981.

MRUÉ, F. Substituição do esôfago cervical por prótese biossintética de látex. Estudo experimental em cães. 1996. Dissertação (Mestrado em Medicina). Faculdade de Medicina, Universidade de São Paulo, Ribeirão Preto, 1996.

NETTO, J.C.; MRUÉ, F. Biomembrana: monografia apresentada à Academia Brasileira de Estudos Avançados. Pele Nova Biotecnologia S/A, Arquivos. São Paulo; 2003.

OLIVEIRA, J.A.A. et al . Miringoplastia com a utilização de um novo material biossintético. RevistaBrasileira de Otorrinolaringologia, v.69, n.5, p. 649-655, set.2003.

OLIVEIRA, E.C.C. et al. Uso de membrana de látex natural em cirurgia de pterígio : apresentação da técnica e dados preliminares. In : CONGRESSO BRASILEIRO DE

OFTALMOLOGIA, 33., 2005, Fortaleza. Anais... Rio de Janeiro : Sociedade Brasileira de Oftalmologia, 2005.

ORTONNE, J.P.; CLÉVY, J.P. Physiologie de la cicatrisation cutanée. Revue de la Pratique Clinique, v.44, n.13, p.1735-1737, set.1994.

PERRY, B.H., SAMPSON, A.R., SCHWAB, B.H., KARIM, M.R., SMIELL, J.M. A metaanalytic approach to an integrated summary of 
efficacy: a case study of becaplermin gel.

Controlled Clinical Trials, v.23, n.4, p.389-408, ago.2002.

PRANDI FILHO, W., SIMÕES, M.J., KULAY

JÚNIOR, L. et al. Aspectos morfológicos e morfométricos do processo inflamatório provocados por fio de algodão no subcutâneo de ratos tratados com diclofenaco sódico. Acta Cirúrgica Brasileira, v.3, p.32-37, 1988.

SADER, S.L. et al. Substituição parcial do pericárdio de cães por membrana de látex natural. Revista Brasileira de Cirurgia Vascular, v.15, n.4, p.338-344, 2000.

TERKELTAUB, R.A.; GINSBERG, M.H. Platelets and response to injury. In: CLARK, R.A.F., HENSON, P.M., ed. The molecular and cellular biology of wound repair. New York: Plenum Press, 1998.

THOMAS, S. Cost of managing chronic wounds in the U.K., with particular emphasis on maggot debridement therapy. Journal of Wound Care, v.15, n.10, p.465-469, nov.2006.
TOGNINI J.R.F. et al. Efeito do diclofenaco de sódio na cicatrização da parede abdominal de ratos. Acta Cirúrgica Brasileira, v.13, n.3, p.167-171, jul.1998.

TOGNINI J.R.F. Estudo biomecânico e morfológico da cicatrização da parede abdominal de ratos sob ação de meloxicam. São Paulo, 1999. 87 p.Tese (Doutorado em Medicina). Escola Paulista de Medicina, Universidade Federal de São Paulo, 1999.

VAN WINKLE. W. The fibroblast in wound healing. Surgery, Gynecology andObstetrics, v.124, n.2, p.369-386, fev.1967.

WINTER, G.D. Formation of the scab and the rate of epithelization of superficial wounds in the skin of the young domestic pig. Nature, v.193, p. 293$295,1962$.

WITTE, M.B.; BARBUL, A. General principles of wound healing. Surgical Clinics of North America, v.77, n.3, p.509-28, jun.1997. 